\title{
Notes on Terminology
}

Throughout our stories and commentary, you will see a variety of names for Indigenous peoples. Where specific to Indigenous peoples of Maine and the Maritimes, the name "Wabanaki" may be used, referring to one of the four recognized tribes: Penobscot, Passamaquoddy, Micmac (in Maine) or Mi'kmaq (in Canada), and Maliseet. In various places you will also see the more traditional spelling of Indigenous names paired with the anglicized version. Other general terminology is also used, and reflects differences between the United States and Canada (for example, "First Nations" and "Aboriginal" are terms commonly used in Canada but not generally in the United States) as well as regional, generational, and personal differences. Sometimes variation in terminology is used to avoid repetition.

"Native" is a term commonly used both in Maine and in Eastern Canada, and is preferred by many Indigenous people to the term "Indian." Conversely, to distinguish the other participants in the Gatherings, we often use the term "non-Native," as well as "White." The stories in this book speak to the relationship between Native North America and White North America - between the original inhabitants of this land and the descendants of European settlers as well as those of European descent who came after the original settlement. We do not attempt to address relationships between Native 
North America and other ethnic or racial groups who came later from Africa or Asia.

All names for Indigenous peoples as well as for Whites and other ethnic/racial groups have been intentionally capitalized, except where appearing in direct quotations from other sources. Other nouns in specific contexts also have been capitalized to denote respect or reverence, such as "Elder," "Earth," "Fire," "Circle," and "Life."

Other differences between United States and Canadian terminology exist. In the United States, the term "reservation" is used for areas of land set aside by the government as tribal homeland; in Canada, the corresponding term is "reserve." In the United States, the governing body of a tribe that was established by act of Congress is referred to as the "tribal council"; in Canada, the corresponding body is referred to as the "band council."

The creation of the United States and Canada, and the resulting border, gave rise over time to these differences in terminology and political structures as they relate to Indigenous peoples, but throughout the years Wabanaki participants in the Gatherings reminded us that the border is simply an imaginary line created by two colonial governments. While this line had meaning for the United States and Canada, it divided and separated Wabanaki families, communities, tribes, sovereign governments, and territories that had, for millennia, existed as one.

In the text to follow, every effort has been made to distinguish clearly between the opinions of Native and non-Native participants of the Gatherings. As a non-Native author, I took care to speak only for myself or for "we non-Natives," and to attribute the thoughts and reflections of Native participants appropriately to them. I use the word "we" in certain places to refer to the group as a whole where 
I am confident, based on the conversations that created this book, that the experience was shared by all.

Finally, in describing the original intention of the Gatherings, I purposely use the word "alliance" rather than, possibly, "coalition." Coalitions are generally formed around a common goal, and when that goal is met they can, and often do, dissolve. Elly Haney, the founder of the Center for Vision and Policy, defines "alliance" in her book The Great Commandment:
Alliances are sustained commitments among groups and individuals to share experiences and insights, pain and rage, dreams and fears, and to engage in collective action for justice. ${ }^{1}$

It was upon this understanding of the concept of alliance that the Gatherings were founded. 
This page intentionally left blank 